\title{
Sub Pixel Classification of High Resolution Satellite Imagery
}

\author{
Mohammed Arif \\ Master of Technology \\ CMR College of Engg \& Tech \\ Kandlakoya, Hyderabad
}

\author{
Merugu Suresh, Kamal Jain \\ Indian Institute of Technology \\ Roorkee, Uttarakhand, India
}

\author{
Sowjanya Dundhigal \\ Assistant Professor \\ CMR College of Engg \& Tech \\ Kandlakoya, Hyderabad
}

\begin{abstract}
The emergences of more Earth observation satellites have increased the use of satellite imagery in applications like Land cover detection, environment monitoring etc. The information is generally extracted from satellite images by classification techniques. A common Problem associated with classification process is frequent occurrence of mixed pixel. Mixed Pixels are major cause of uncertainty in image classification process. Soft classifiers provide quantitative presence of a class in a pixel but the spatial location of this class remains unexplored. Subpixel classification and swapping have evolved as a latest technique to generate superior subpixel swapping images by considering output of soft classification process. SRM algorithms are mainly classified as spatial optimization based and regression based approaches. However the spatial optimization techniques are more applicable. The major drawback of conventional techniques is non-random allocation of classes to sub pixels which leads to iterative procedure of optimization that is time taking. In this paper, the proposed method performs an initial non-random allocation of classes to sub pixel and optimization procedure adapted is performed to overcome multiple and non-allocated sub pixels to simplify SRM approach and curtail processing time. Proposed method uses soft classification approaches for generating fractional maps which is provided as input to SRM method. Early allocation of sub pixels is achieved based on amount of attractiveness to neighborhood pixels.
\end{abstract}

\section{General Terms}

Subpixel targets, full pixel, soft classification, and high resolution images etc.

\section{Keywords}

Subpixel mapping, subpixel classification, satellite images, landuse landcover and remote sensing data.

\section{INTRODUCTION}

The most important technique in remote sensing imaging is image classification which is widely used to extract land cover information and have an important use in environment monitoring and mineral exploration. Accurate information of land cover has an appropriate importance for environment outlining and other issues. So it is necessary to reduce the uncertainty in various steps of extracting meaningful data from the land cover. Remote sensing image contains a mix of pure and mixed pixels. Pure pixel contains only one feature such as vegetation or urban area while mixed pixel defined as pixel containing more than one feature. Mixed pixel occurs when the interval between pixels is less than the spatial frequency. Mixed pixel affects the accuracy of classification process. Without overcoming the issue of mixed pixel, the possibility of extracting meaningful data will remain unrealized (Foody, 2006).

The properties of land cover maps extracted from various images through classification technologies are not always the same and also has been a difficult task (Bonnet and Campbell 2002) (M Suresh \& K Jain 2013\&14). Since the land cover has at least more than one class, mixed pixel problem occurs in deriving meaningful information from data acquired (Fisher 1997, Cracknell 1998 and M Suresh 2015). The sub pixel target and resolved or full pixel target can be seen in Fig.1.

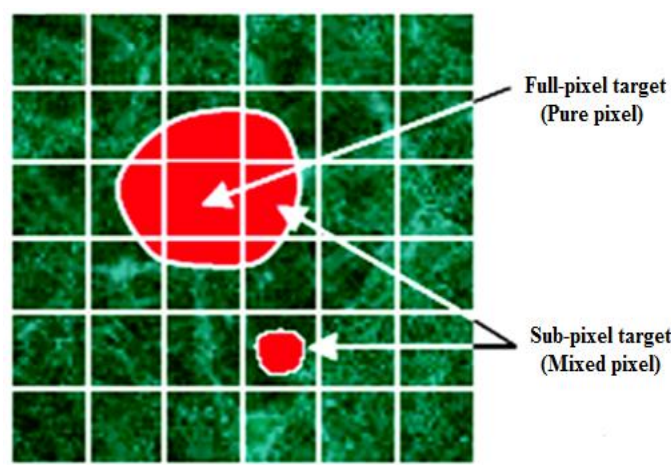

Figure 1: Full and sub pixel targets

Hard classification or crisp classification assigns only a single class to a pixel in case of mixed pixel and the corresponding mixed pixel is assigned with the dominant class. Hard or crisp classification is easier to process and interpret but there occurs loss of information. To overcome problem associated with hard classifiers soft classification or fuzzy classifiers were introduced in which pixel can belong to more than one class. Soft classification has advantage that it contains more information as compared to hard classification. Soft classification methods evaluate the fraction ratio of land information within the pixel. It enhances the accuracy of classification however failed to estimate spatial position of land cover features as a result the resultant information still contain ambiguity. So it is necessary to estimate spatial location of each class for extracting meaningful data in remote sensing process (Atkinson1997; Tatem et al. 2001) (M Suresh \& A Tiwari, 2014).

\section{RELATED WORK}

The pixel is usually considered as an arbitrary spatial unit. The fundamental characteristics of a pixel like shape, location and size are evaluated mostly by the sensor. They do not depend on characteristics of earth's surface. Generally, a pixel represents more than one class or land cover type. This condition occurs for a variety of reasons and the data acquired from remote sensing process cannot be used directly. Also 
conventional image classification methods fail to classify various land cover types. Hard classification technique is able to classify only one land cover feature and it does not distinguish mixed pixel from pure pixel. Therefore, the occurrence of subpixels will create an error in the classification process. Hence the proportion of mixed pixels in remote sensing data is related to magnitude of this error. Consequently, remote sensing studies always has problem of mixed pixels and it is often large in this case study. Hence, the solution to resolve mixed pixel problem has got importance in achieving good accuracy in classification process.

Feng Ling et al. (2010) proposed a method to reduce the problem of mixed pixel in classification process and to evaluate spatial value position of each land cover feature within a mixed pixel using super resolution process. From this work, fractional images for low resolution remote sensing images are achieved using soft classification approach. To attain high resolution land cover map these fractional images are used as an input to the super resolution mapping technique. From the experiments it was observed that, high overall accuracy and better kappa coefficients are achieved in the final output with low scale factor and more fractional images.

According to Niroumand et al. (2012) the classification of remote sensing images has always been typical due to frequent occurrence of mixed pixel. At this instant, soft classifiers are often inevitable to achieve good accuracy in classification process. But using the output of soft classification process, super resolution mapping can generate finer spatial resolution maps. This clearly indicates the importance of spatial optimization algorithms. However, the main drawbacks of current method are allocation of sub pixels inside a coarse pixel is done at random and the optimization approach employed in this technique is an iterative process. In his work, pixel swapping technique based optimization approach is implemented and also concludes that the procedure is time effective.

Feng Ling and Yun Du (2013) proposed super resolution land cover mapping using interpolation techniques in which a twostep super resolution mapping approach is implemented. Initially, fractional images for each land cover types are achieved using soft classification for a remotely sensed image and then indicator maps are produced for each fractional image. In the next step all indicator maps are combined to generate a final fine resolution indicator map. In this paper Spline, Kriging and Inverse Distance Weighted (IDW) interpolation methods were used. In addition to these methods four indicator map combination approaches including the sequential assignment approach and the maximal value approach with normalization and without normalization were assessed.

Manoj K. Arora and K.C. Tiwari (2013) proposed a superresolution mapping with the help of new inverse Euclidean distance in which the sub pixel target detection is performed by adjusting spatial arrangement of fraction area of each land cover type within a pixel of a hyper spectral image. The super-resolution mapping technique may effectively be utilized in enhancing the target detection at sub-pixel level based on results obtained at different resolutions.

Qunming Wang, Wenzhong Shi et al. (2014) introduced a new approach for sub-pixel mapping based on radial basis function interpolation for land cover mapping at sub-pixel level. In this paper RBF interpolation process was used to allocate land cover feature type for every sub-pixel. This process includes three stages to predict soft class values for each sub-pixel. First, spatial relations are determined between a visited coarse pixel and sub pixel. Second, coefficients are calculated for neighboring coarse pixels indicating the contributions. Third, sub-pixel soft class values are estimated using the basis function values weighted by coefficients. This proposed method was tested on three different remote sensing images and the test results were compared to existing bilinear, bi-cubic, sub-pixel spatial attraction model and kriging-based SPM methods. It can be concluded that the proposed method gives more accurate results than earlier stated techniques.

\section{EXPERIMENTAL DATA}

The study area of hyper spectral images (satellite imagery) discussed in this paper is categorized into two parts viz., AVIRIS dataset and Aerial image.

\subsection{AVIRIS dataset}

The hyper spectral data used in our case study downloaded from the AVIRS Free Standard Data Products Downloads Page at the NASA JPL website, at $\mathrm{http} / / / a v i r i s . j p l . n a s a . g o v / h t m l / a v i r i s . f r e e d a t a . h t m l$. This is the Moffett Field sample image in reflectance that was collected in 1997. The AVIRIS dataset used in our discussion are shown in Fig. 2 (a), (b) \& (c).

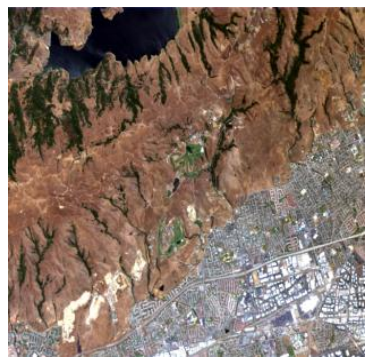

(a)

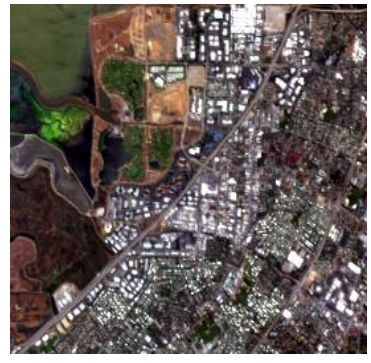

(c)

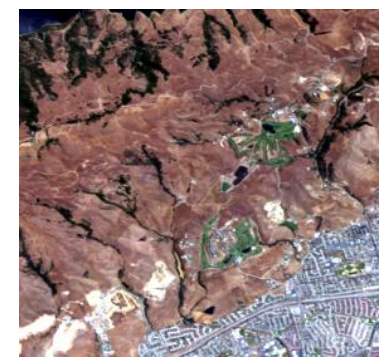

(b)

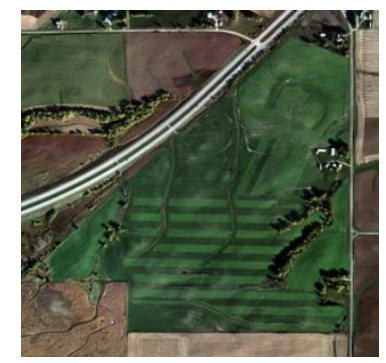

(d)
Figure 2: Experimental dataset

\section{(a) AVIRIS Flight Run1 (b) Subset of AVIRIS Flight Run1 (c) Subset of AVIRIS Flight Run3 (d) Aerial image}

The AVIRIS Moffetfield Reflectance Flight Run1 image consists of 614 samples, 512 lines and 224 bands from which a selected band combination of $R, G$ and $B(R=29, G=19$, $\mathrm{B}=9$ ) displays purview of the entire image.

The subset of AVIRIS Moffetfield Reflectance Flight Run1 image consists of 286 samples, 388 lines and 204 bands from which a selected band combination of $R, G$ and $B(R=26$, $\mathrm{G}=16, \mathrm{~B}=6$ ) displays purview of the entire image.

The subset of AVIRIS Moffetfield Reflectance Flight Run3 image consists of 270 samples, 242 lines and 204 bands from which a selected band combination of $R, G$ and $B(R=26$, $\mathrm{G}=16, \mathrm{~B}=6$ ) displays purview of the entire image. 


\subsection{Aerial image}

The aerial image downloaded from the website http://geovantage.com/applications/precision-agriculture/.

Aerial imagery is an essential component in utilizing precision agriculture techniques for the management of farmland. Precision agriculture is a widely accepted practice. The study image consists of $942 \times 1024$ pixels with three bands R, G and $\mathrm{B}$ available to the display. The aerial image involved in our discussion is shown in Fig. 2(d).

\section{METHODOLOGY}

At first, the dataset used in our experiments were classified using supervised Support Vector Machine model. In which, we have employed trained regions of interest as trained data to perform classification. SVM is a classification system extracted from the theory of statistical learning model. The classes are separated with a decision surface that maximizes the margin between the classes. The decision surface is also called as optimal hyper plane, and the data points nearer to the hyper plane are known as support vectors which are the critical elements of the training set.

Though SVM is a binary classifier, creating a binary classifier for each possible pair of classes it can function as a multiclass classifier. Since this model also exhibits pair wise classification strategy for multiclass classification. The output of SVM classification results decision values of each pixel for each class, which are used for probability estimates. The probability values of rule images represent "true" probability in the sense that each probability value is in the range of 0 to 1; also the sum of probability values for each pixel equals to 1. Finally, SVM performs classification by choosing the highest probability. A threshold value which can be adjusted allows reporting pixels with all probability values less than the threshold as unclassified. This method provides good classification results from complex and noisy data but able to identify only the class associated with each pixel.

The proposed method of subpixel classification and mapping can be categorized as spatial based or spatial optimization based techniques. The aim is to overcome the problem of existing techniques i.e., allocation of sub pixels done at random and optimization approach employed which is generally an iterative model. The algorithm starts with results of soft classification as input to produce a hard classified finer spatial resolution image as shown in Figure 3.

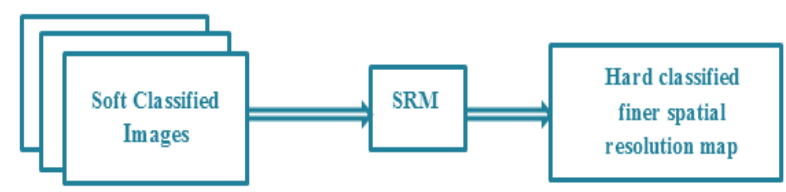

Figure 3: Process of super resolution mapping

The spatial optimization based sub pixel mapping techniques are developed with an aim to maximize spatial relation between similar clusters. The fraction image resulted from soft classification contains certain portion of mixed pixels assigned to an appropriate class feature within a pixel. The spatial optimization techniques regulate mixed pixels such that the spatial dependency between pixels and mixed pixels is improved.

To deal with problem of uncertainty in spatial location SPM (Sub pixel Mapping) was introduced in which each pixel is split in to numerous sub pixels. Each mixedpixels is allocates to a particular ground cover feature using different techniques, and thus transforming into a better enhanced hard classification image from the output of soft classification processed image (Verhoeye et al., 2002). A generalized path flow of above description is shown in Figure 3.

Subpixel swapping is also referred as SPM in classification of remote sensing process (Atkinson 2009). Super resolution techniques reduces the spatial uncertainty in outputs obtained from soft classifiers by making spatial adjustments of the sub pixels by using magnitude of classes inside a pixel. The input to SR technique is the fractional maps generated by soft classification methods. Usually accuracy of sub pixel mapping method depends on accuracy of soft classification method (M Suresh \& K Jain 2014).

In this paper, high resolution images are used to test the proposed method, this data has been used as reference. Experiments are also performed on hyper spectral images which are taken from AVIRIS sensor dataset and aerial image. The proposed method in this study is summarized below.

a) Initially, the abundance fractions for different land cover types.

b) Estimate the zoom factor for SRM.

c) The attractiveness between class center and each sub pixel is calculated.

d) Consider the fractional area for a particular class in all neighborhood pixels related to the target pixel. Then based on this factor assign sub pixels to neighborhood clique pixels.

e) Then the clique pixel is super-resolved based on fractional area of each class.

f) Based on attractiveness ranking calculated at step (c) for this clique pixel, the sub pixels related with this pixel are spatially distributed.

g) Finally, the steps from (a) to (f) are repeated until all the clique pixels have taken into consideration. To avoid overlapping problem in sub pixels next vacant location can be utilized.

One of the main advantages of this algorithm is near constant CPU execution time despite there is a change in zoom factor. Though the employed algorithm gives better results, and this method does not consider the spatial dependency associated within the pixels.

The proposed SRM technique initial allocation of classes to sub pixel is done in a nonrandom manner i.e., on basis of class proportions and distances. Then the spatial dependency is increased using an iterative optimization procedure. The major constraint followed throughout the SRM procedure is to maintain the original class fractions within the pixel.

To describe our algorithm, let an image contains $m x n$ pixels. On applying scale factor (zoom factor) $S$. Sub pixels are numbered as $i=1,2,3 \ldots \ldots S^{2}, \mathrm{j}$ representing class in image $(j=1,2,3 \ldots$ number of classes $)$. A schematic diagram representing image parameters is shown in Figure 4. 


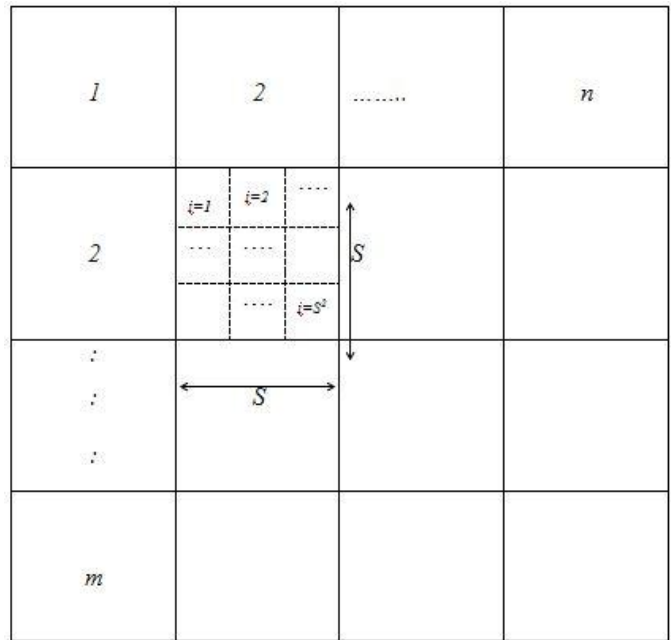

Figure 4: Schematic representation of image parameters

The process of optimization is performed one by one on each pixel to guarantee preservance of original class proportions. Image is scanned to find multiple and non-allocated sub pixel The value of maximum attractiveness for selected pixels are sorted in decreasing order. The binary variable related to maximum amount of maximum attractiveness is kept as it is in multiple allocated sub pixel. Then the next highest value of maximum attractiveness is selected and corresponding value mapped with mixed pixel that is not accommodated to any feature. The procedure continues till all mixed pixels will accommodate with only single class. The steps of proposed SRM algorithm are summarized as follows:

- Estimate number of mixed pixels for a coarse pixel based on scale factor.

- Calculate distance between neighborhood pixel and mixed pixel.

- Predict soft class value for particular class for each mixed pixel.

- Estimate soft class value which is a weighted linear combination of $\mathrm{N}$ values.

- Describe the spatial relation between mixed pixel and the neighborhood pixels.

\section{RESULTS AND DISCUSSIONS}

The performance of proposed method evaluated using different data i.e., AVIRIS data and Aerial image. The generated results of these data after performing soft classification and proposed super resolution mapping technique are shown in fig. 5 to 8 . The accuracy assessment of these techniques and its measures like overall accuracy, producer's accuracy, user's accuracy and kappa coefficient are discussed below:

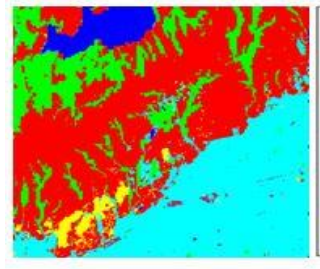

Hard classified output
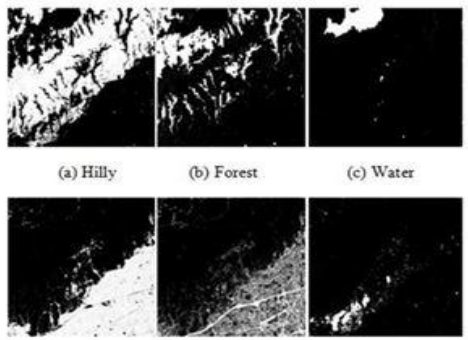

(d) Urban

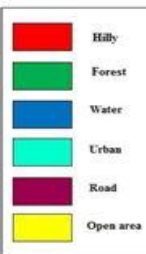

Opea ares

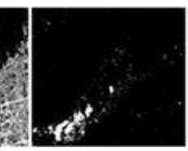

(f) Open area

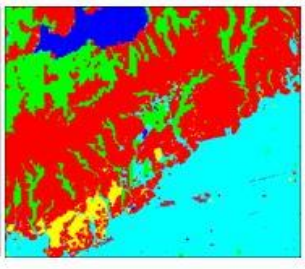

SRM output

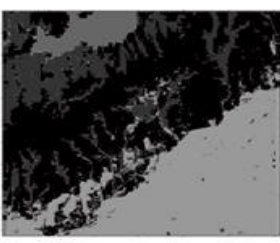

Binary image
Figure 5: Experimental results of AVIRIS Flight Run1

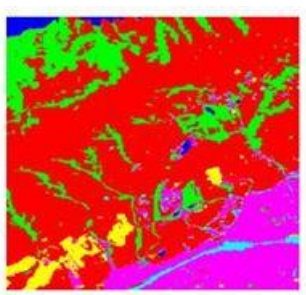

Hard classified output

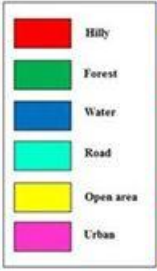

intus

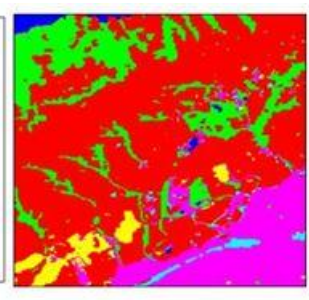

SRM output

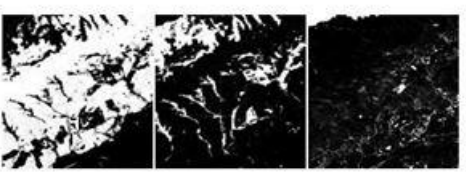

(a) Hilly

(b) Forest

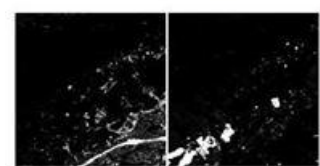

(d) Road (c) Water

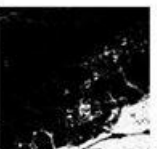

(d) Urban

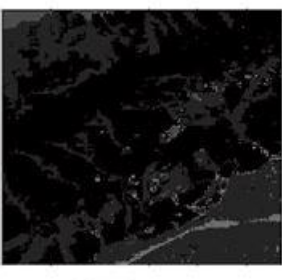

Binary image

Figure 6: Experimental results of subset of AVIRIS Flight Run1

In each of the resulting output of our implemented experimental data we have generated hard classified output, SRM output, and fractional images of each land cover and binary output as our classified results. The error matrix showing all the above accuracy assessment measures are shown in tables 1 to 4 . It can be observed that the overall classification accuracy increases from soft classification process to proposed SRM algorithm. Similarly, a slight improvement in kappa coefficient is also seen between the two approaches. In all cases, the $\mathrm{K}$ value is greater than 0.75 and hence we can say that the results are more accurate and stable.

6. CONCLUSION AND FUTURE SCOPE

The proposed super resolution mapping technique provides super resolved land cover information using the output of soft classification process. 


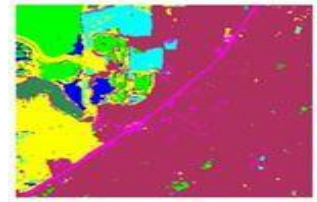

Hard classified output

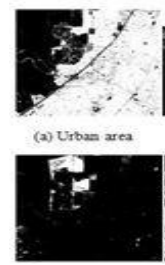

(d) Open area

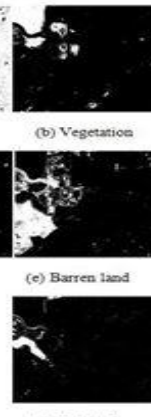

(s) Wet land
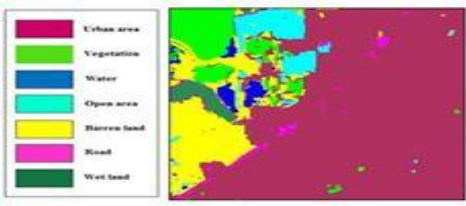

SRM output

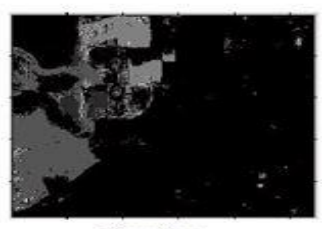

Binary image
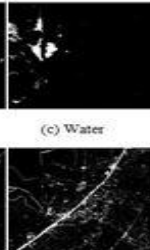

(f) Roas
Figure 7: Experimental results of subset of AVIRIS Flight Run3

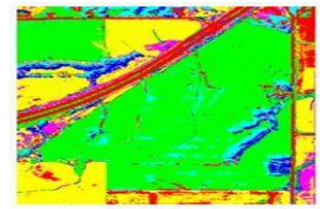

Hard classified output

(d) Shadow

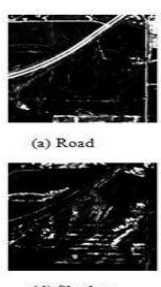

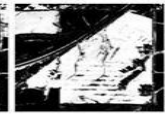

(b) Vegetation

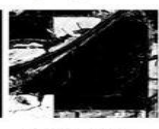

(e) Open area
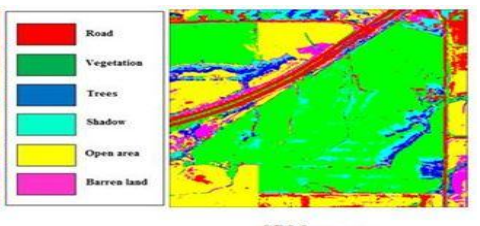

SRM output

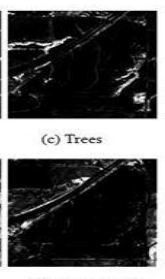

(f) Barren land

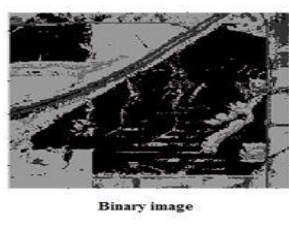

Figure 8: Experimental results of Aerial image

The output of soft classifier satisfies the constraint of nonnegativity and sum to unity of fractional abundance within the pixels. A combination of supervised and unsupervised sub pixel classification algorithms was used to obtain fractional images. The combination of two methods was used to ensure the fulfillment of two constraints. The non-random allocation of sub pixel is considered as the main part of work for the super resolution mapping procedure. Latest conventional algorithms of super resolution mapping frequently use random initial allocation and recursive optimization approach.

Table 1(a): Error matrix of AVIRIS Flight Run 1 after performing soft classification

\begin{tabular}{|c|c|c|c|c|c|c|c|c|c|}
\hline & Hilly & Forest & Water & Urban & Road & $\begin{array}{c}\text { Open } \\
\text { area }\end{array}$ & Total & $\begin{array}{c}\text { Producers } \\
\text { Accuracy }\end{array}$ & $\begin{array}{c}\text { Users } \\
\text { Accuracy }\end{array}$ \\
\hline Unclassified & 0.00 & 0.00 & 0.00 & 0.00 & 0.00 & 0.00 & 0.00 & & \\
\hline Hilly & $\mathbf{9 8 . 5 9}$ & 2.05 & 0.04 & 0.39 & 2.45 & 3.44 & 32.36 & $98.59 \%$ & $98.37 \%$ \\
\hline Forest & 0.62 & 95.47 & 0.01 & 0.38 & 0.00 & 0.00 & 8.26 & $95.47 \%$ & $95.47 \%$ \\
\hline Water & 0.00 & 0.10 & 99.94 & 0.05 & 0.00 & 0.00 & 7.81 & $99.94 \%$ & $99.59 \%$ \\
\hline Urban & 0.53 & 2.25 & 0.01 & 98.77 & 86.68 & 5.29 & 48.82 & $98.77 \%$ & $91.67 \%$ \\
\hline Road & 0.00 & 0.00 & 0.00 & 0.31 & $\mathbf{1 0 . 6 0}$ & 0.00 & 0.58 & $10.60 \%$ & $75.56 \%$ \\
\hline Open area & 0.26 & 0.13 & 0.00 & 0.09 & 0.26 & 91.27 & 2.17 & $91.27 \%$ & $93.33 \%$ \\
\hline Total & 100.00 & 100.00 & 100.00 & 100.00 & $\mathbf{1 0 0 . 0 0}$ & $\mathbf{1 0 0 . 0 0}$ & $\mathbf{1 0 0 . 0 0}$ & & \\
\hline
\end{tabular}

Overall Classification Accuracy $=94.7135 \%$

Kappa Coefficient $=0.9200$
Table 1(b): Error matrix of AVIRIS Flight Run 1 after performing proposed SRM

\begin{tabular}{|c|c|c|c|c|c|c|c|c|c|}
\hline & Hilly & Forest & Water & Urban & Road & $\begin{array}{c}\text { Open } \\
\text { area }\end{array}$ & Total & $\begin{array}{c}\text { Producers } \\
\text { Accuracy }\end{array}$ & $\begin{array}{c}\text { Users } \\
\text { Accuracy }\end{array}$ \\
\hline Unclassified & 0.08 & 0.32 & 0.01 & 0.00 & 0.00 & 0.03 & 0.05 & & \\
\hline Hilly & 08.44 & 1.64 & 0.04 & 0.16 & 1.65 & 2.66 & 32.12 & $98.44 \%$ & $98.95 \%$ \\
\hline Forest & 0.62 & 95.20 & 0.01 & 0.21 & 0.00 & 0.00 & 8.16 & $95.20 \%$ & $96.39 \%$ \\
\hline Water & 0.00 & 0.09 & 99.94 & 0.04 & 0.00 & 0.00 & 7.80 & $99.94 \%$ & $99.66 \%$ \\
\hline Urban & 0.60 & 2.63 & 0.00 & 99.17 & 87.12 & 1.56 & 48.99 & $99.17 \%$ & $91.73 \%$ \\
\hline Road & 0.00 & 0.00 & 0.00 & 0.34 & $\mathbf{1 1 . 0 2}$ & 0.00 & 0.61 & $11.02 \%$ & $74.91 \%$ \\
\hline Open area & 0.25 & 0.12 & 0.00 & 0.09 & 0.21 & 95.75 & 2.26 & $95.75 \%$ & $93.83 \%$ \\
\hline Total & $\mathbf{1 0 0 . 0 0}$ & $\mathbf{1 0 0 . 0 0}$ & $\mathbf{1 0 0 . 0 0}$ & $\mathbf{1 0 0 . 0 0}$ & $\mathbf{1 0 0 . 0 0}$ & $\mathbf{1 0 0 . 0 0}$ & $\mathbf{1 0 0 . 0 0}$ & & \\
\hline
\end{tabular}

Overall Classification Accuracy $=94.9398 \%$ Kappa Coefficient $=0.9234$

Table 2(a): Error matrix of subset of AVIRIS Flight Run 1 after performing soft classification

\begin{tabular}{|c|c|c|c|c|c|c|c|c|c|}
\hline & Hilly & Forest & Water & Road & $\begin{array}{c}\text { Open } \\
\text { area }\end{array}$ & Urban & Total & $\begin{array}{c}\text { Producers } \\
\text { Accuracy }\end{array}$ & $\begin{array}{c}\text { Users } \\
\text { Accuracy }\end{array}$ \\
\hline Unclassified & 0.00 & 0.00 & 0.00 & 0.00 & 0.00 & 0.00 & 0.00 & & \\
\hline Hilly & 98.75 & 3.91 & 0.00 & 3.31 & 2.50 & 0.57 & 48.05 & $98.75 \%$ & $98.00 \%$ \\
\hline Forest & 0.77 & 95.16 & 0.00 & 0.00 & 0.00 & 1.10 & 13.58 & $95.16 \%$ & $95.07 \%$ \\
\hline Water & 0.00 & 0.05 & 100.00 & 0.00 & 0.00 & 0.00 & 1.39 & $100.00 \%$ & $99.55 \%$ \\
\hline Road & 0.05 & 0.07 & 0.00 & 60.87 & 0.27 & 1.13 & 2.76 & $60.87 \%$ & $86.85 \%$ \\
\hline Open area & 0.38 & 0.09 & 0.00 & 0.24 & 94.08 & 0.47 & 5.70 & $94.08 \%$ & $94.13 \%$ \\
\hline Urban & 0.05 & 0.73 & 0.00 & 35.59 & 3.15 & 96.73 & 28.51 & $96.73 \%$ & $94.03 \%$ \\
\hline Total & 100.00 & 100.00 & 100.00 & 100.00 & 100.00 & 100.00 & 100.00 & & \\
\hline
\end{tabular}

Overall Classification Accuracy $=95.9634 \%$

Kappa Coefficient $=0.9396$

In this study, an algorithm is used for non-random initial allocation of sub pixel. The overall accuracy of SRM algorithm depends on certain factors like the accuracy of soft classification process, scale factor, the window size for neighbor consideration, and optimization algorithm. Evaluation on these distinct parameters requires more research which is remain as open for future scope.

Table 2(b): Error matrix of subset of AVIRIS Flight Run1 after performing proposed SRM

\begin{tabular}{|c|c|c|c|c|c|c|c|c|c|}
\hline & Hilly & Forest & Water & Road & $\begin{array}{c}\text { Open } \\
\text { area }\end{array}$ & Urban & Total & $\begin{array}{c}\text { Producers } \\
\text { Accuracy }\end{array}$ & $\begin{array}{c}\text { Users } \\
\text { Accuracy }\end{array}$ \\
\hline Unclassified & 0.11 & 0.07 & 0.00 & 0.24 & 0.33 & 0.00 & 0.09 & & \\
\hline Hilly & 98.63 & 2.03 & 0.00 & 2.52 & 1.90 & 0.03 & 47.53 & $98.63 \%$ & $98.96 \%$ \\
\hline Forest & 0.79 & 97.05 & 0.00 & 0.00 & 0.00 & 0.43 & 13.67 & $97.05 \%$ & $96.37 \%$ \\
\hline Water & 0.00 & 0.05 & 100.00 & 0.00 & 0.00 & 0.00 & 1.39 & $100.00 \%$ & $99.55 \%$ \\
\hline Road & 0.04 & 0.05 & 0.00 & 52.44 & 0.00 & 0.06 & 2.11 & $52.44 \%$ & $98.09 \%$ \\
\hline Open area & 0.40 & 0.07 & 0.00 & 0.08 & 93.91 & 0.36 & 5.66 & $93.91 \%$ & $94.68 \%$ \\
\hline Urban & 0.03 & 0.69 & 0.00 & 44.72 & 3.86 & 99.13 & 29.56 & $99.13 \%$ & $92.94 \%$ \\
\hline Total & 100.00 & 100.00 & 100.00 & 100.00 & 100.00 & 100.00 & 100.00 & & \\
\hline
\end{tabular}

Overall Classification Accuracy $=96.4874 \%$ Kappa Coefficient $=0.9475$ 
Table 3(a): Error matrix of subset of AVIRIS Flight Run 3 after performing soft classification

\begin{tabular}{|c|c|c|c|c|c|c|c|c|c|c|}
\hline & Vegetation & Water & $\begin{array}{c}\text { Barren } \\
\text { land }\end{array}$ & $\begin{array}{c}\text { Open } \\
\text { area }\end{array}$ & Road & $\begin{array}{c}\text { Urban } \\
\text { area }\end{array}$ & $\begin{array}{c}\text { Wet } \\
\text { land }\end{array}$ & Total & $\begin{array}{c}\text { Producers } \\
\text { Accuracy }\end{array}$ & $\begin{array}{c}\text { Users } \\
\text { Accuracy }\end{array}$ \\
\hline Unclassified & 0.00 & 0.00 & 0.00 & 0.00 & 0.00 & 0.00 & 0.00 & 0.00 & & \\
\hline Vegetation & 97.25 & 0.00 & 0.20 & 0.13 & 0.00 & 0.17 & 0.20 & 10.72 & $97.25 \%$ & $98.67 \%$ \\
\hline Water & 0.03 & 92.75 & 1.01 & 0.00 & 0.00 & 0.00 & 0.00 & 1.72 & $92.75 \%$ & $90.69 \%$ \\
\hline Barrenland & 0.13 & 7.25 & 95.36 & 5.64 & 1.89 & 0.40 & 2.21 & 15.68 & $95.36 \%$ & $94.56 \%$ \\
\hline Open area & 0.00 & 0.00 & 2.13 & 93.52 & 0.00 & 0.27 & 0.00 & 5.52 & $93.52 \%$ & $91.16 \%$ \\
\hline Road & 0.00 & 0.00 & 0.22 & 0.06 & 53.78 & 1.15 & 2.31 & 3.85 & $53.78 \%$ & $79.82 \%$ \\
\hline Urban area & 2.53 & 0.00 & 0.94 & 0.65 & 44.27 & 98.01 & 1.41 & 59.22 & $98.01 \%$ & $94.88 \%$ \\
\hline Wet land & 0.06 & 0.00 & 0.13 & 0.00 & 0.06 & 0.00 & 93.87 & 3.29 & $93.87 \%$ & $99.05 \%$ \\
\hline Total & 100.00 & 100.00 & 100.00 & 100.00 & 100.00 & 100.00 & 100.00 & 100.00 & & \\
\hline
\end{tabular}

Overall Classification Accuracy $=94.2515 \%$

Kappa Coefficient $=0.9051$

Table 3(b): Error matrix of subset of AVIRIS Flight Run3 after performing proposed SRM

\begin{tabular}{|c|c|c|c|c|c|c|c|c|c|c|}
\hline & Vegetation & Water & $\begin{array}{c}\text { Barren } \\
\text { land }\end{array}$ & $\begin{array}{c}\text { Open } \\
\text { area }\end{array}$ & Road & $\begin{array}{c}\text { Urban } \\
\text { area }\end{array}$ & $\begin{array}{c}\text { Wet } \\
\text { land }\end{array}$ & Total & $\begin{array}{c}\text { Producers } \\
\text { Accuracy }\end{array}$ & $\begin{array}{c}\text { Users } \\
\text { Accuracy }\end{array}$ \\
\hline Unclassified & 0.19 & 0.00 & 0.49 & 0.00 & 0.00 & 0.05 & 0.30 & 0.14 & & \\
\hline Vegetation & 96.93 & 0.00 & 0.00 & 0.13 & 0.00 & 0.00 & 0.20 & 10.56 & $96.93 \%$ & $99.87 \%$ \\
\hline Water & 0.00 & 91.10 & 0.40 & 0.00 & 0.00 & 0.00 & 0.00 & 1.60 & $91.10 \%$ & $96.07 \%$ \\
\hline $\begin{array}{c}\text { Barren } \\
\text { land }\end{array}$ & 0.00 & 8.90 & 95.47 & 0.78 & 1.34 & 0.17 & 0.80 & 15.24 & $95.47 \%$ & $97.42 \%$ \\
\hline Open area & 0.00 & 0.00 & 2.40 & 98.44 & 0.00 & 0.12 & 0.00 & 5.73 & $98.44 \%$ & $92.34 \%$ \\
\hline Road & 0.00 & 0.00 & 0.13 & 0.00 & 27.74 & 0.06 & 1.41 & 1.69 & $27.74 \%$ & $93.81 \%$ \\
\hline Urban area & 2.88 & 0.00 & 0.99 & 0.65 & 70.91 & 99.60 & 0.70 & 61.08 & $99.60 \%$ & $92.58 \%$ \\
\hline Wetland & 0.00 & 0.00 & 0.11 & 0.00 & 0.00 & 0.00 & 96.58 & 3.37 & $96.58 \%$ & $99.48 \%$ \\
\hline Total & 100.00 & 100.00 & 100.00 & 100.00 & 100.00 & 100.00 & 100.00 & 100.00 & & \\
\hline
\end{tabular}

Overall Classification Accuracy $=94.5128 \%$

Kappa Coefficient $=0.9112$

The proposed super resolution mapping algorithm presented in our study is also useful for super resolution reconstruction. In this case spatially resolved remote sensing images can be used as an input. The output of super resolution mapping algorithm will be a desired multispectral or hyper spectral image obtained at a fine spatial resolution of land cover maps. Our future study will focus on this.

Table 4(a): Error matrix of subset of Aerial image after performing soft classification

\begin{tabular}{|c|c|c|c|c|c|c|c|c|c|}
\hline & Vegetation & Road & Trees & $\begin{array}{c}\text { Open } \\
\text { area }\end{array}$ & Shadow & $\begin{array}{c}\text { Barren } \\
\text { Land }\end{array}$ & Total & $\begin{array}{c}\text { Producers } \\
\text { Accuracy }\end{array}$ & $\begin{array}{c}\text { Isers } \\
\text { Accuracy }\end{array}$ \\
\hline Unclassified & 0.00 & 0.00 & 0.00 & 0.00 & 0.00 & 0.00 & 0.00 & & \\
\hline Vegetation & 99.25 & 3.07 & 14.76 & 0.20 & 9.90 & 0.00 & 58.85 & $99.25 \%$ & $98.69 \%$ \\
\hline Road & 0.07 & 91.41 & 2.14 & 0.53 & 1.21 & 0.50 & 4.96 & $91.41 \%$ & $94.29 \%$ \\
\hline Trees & 0.04 & 0.51 & 65.62 & 0.14 & 1.32 & 0.77 & 1.40 & $65.62 \%$ & $88.31 \%$ \\
\hline Open area & 0.17 & 3.69 & 3.74 & 97.86 & 0.11 & 63.74 & 29.54 & $97.86 \%$ & $87.45 \%$ \\
\hline Shadow & 0.47 & 0.00 & 10.35 & 0.00 & 87.07 & 0.09 & 2.94 & $87.07 \%$ & $83.79 \%$ \\
\hline $\begin{array}{c}\text { Barren } \\
\text { land }\end{array}$ & 0.00 & 1.33 & 3.39 & 1.26 & 0.40 & 34.89 & 2.31 & $34.89 \%$ & $79.37 \%$ \\
\hline Total & 100.00 & 100.00 & 100.00 & 100.00 & 100.00 & 100.00 & 100.00 & & \\
\hline
\end{tabular}

Overall Classification Accuracy $=94.1256 \%$ Kappa Coefficient $=0.8974$
Table 4(b): Error matrix of subset of Aerial image after performing proposed SRM

\begin{tabular}{|c|c|c|c|c|c|c|c|c|c|}
\hline & Vegetation & Road & Trees & $\begin{array}{c}\text { Open } \\
\text { area }\end{array}$ & Shadow & $\begin{array}{c}\text { Barren } \\
\text { Land }\end{array}$ & Total & $\begin{array}{l}\text { Producers } \\
\text { Accuracy }\end{array}$ & $\begin{array}{c}\text { Users } \\
\text { Accuracy }\end{array}$ \\
\hline Unclassified & 0.00 & 0.07 & 0.45 & 0.16 & 0.06 & 0.00 & 0.06 & & \\
\hline Vegetation & 99.16 & 3.01 & 11.31 & 0.06 & 9.13 & 0.00 & 58.68 & $99.16 \%$ & $98.91 \%$ \\
\hline Road & 0.06 & 91.27 & 1.60 & 0.50 & 1.00 & 0.03 & 4.90 & $91.27 \%$ & $95.36 \%$ \\
\hline Trees & 0.03 & 0.52 & 68.12 & 0.04 & 1.15 & 0.31 & 1.39 & $68.12 \%$ & $92.49 \%$ \\
\hline Open area & 0.19 & 3.75 & 3.48 & 97.90 & 0.13 & 60.24 & 29.38 & $97.90 \%$ & $87.97 \%$ \\
\hline Shadow & 0.55 & 0.00 & 11.47 & 0.00 & 88.19 & 0.05 & 3.04 & $88.19 \%$ & $82.12 \%$ \\
\hline $\begin{array}{c}\text { Barren } \\
\text { land }\end{array}$ & 0.00 & 1.39 & 3.58 & 1.33 & 0.34 & 39.37 & 2.57 & $39.37 \%$ & $80.53 \%$ \\
\hline Total & 100.00 & 100.00 & 100.00 & 100.00 & 100.00 & 100.00 & 100.00 & & \\
\hline
\end{tabular}

Overall Classification Accuracy $=94.3937 \%$

Kappa Coefficient $=0.9023$

\section{REFERENCES}

[1] Anuj Tiwari, Merugu Suresh, Arun Kumar Rai, 2014, "Ecological Planning for Sustainable Development with a Green Technology: GIS", International Journal of Advanced Research in Computer Engineering \& Technology (IJARCET), Volume 3 Issue 3, March 2014, ISSN: $2278-1323$, pp 636-641.

[2] Atkinson P.M., (1997) "Mapping Sub pixel Boundaries From Remotely Sensed Images." Innovations in GIS4, Z.Kemp, Ed.Bristol, PA:Taylor \& Francis, pp.166- 169.

[3] Atkinson, P.M. (2009), "Issues of uncertainty in superresolution mapping and their implications for the design of an inter-comparison study", International Journal of Remote Sensing, 30 (20), 5293-5308.

[4] CRACKNELL, A.P., 1998, Synergy in remote sensing what's in a pixel? International Journal of Remote Sensing, 19, pp. 2025-2047.

[5] Feng Ling and Yun du et al., "Interpolation-based superresolution land cover mapping", Remote Sensing Letters, Vol. 4, No. 7, 629-638, 2013.

[6] Feng Ling et al. (2010), "Super resolution land cover mapping using multiple sub-pixel shifted remotely sensed images", International Journal of Remote Sensing, Vol. 31, No. 19 , pp. 5023-5040.

[7] FISHER, P., 1997, The pixel: A snare and a delusion. International Journal of Remote Sensing, 18,pp. 679-685.

[8] Foody, G.M. (2006). Sub-Pixel Methods in Remote Sensing. In: Jong, S. M. D. and Meer, F. D. v. d. (Eds.), Remote Sensing Image Analysis. Springer.

[9] Manoj K. Arora and K.C. Tiwari (2013), "Subpixel target enhancement in hyperspectral images", Defence science journal, Vol.63, pp. 63-68.

[10] Merugu Suresh, Kamal Jain, 2013, "Colorimetrically Resolution Enhancement Method for Satellite Imagery to Improve Land Use" $14^{\text {th }}$ ESRI User Conference id: UCP0046, New Delhi, India, 11-12 ${ }^{\text {th }}$ Dec, 2013.

[11] Merugu Suresh, Kamal Jain, 2015, "Semantic Driven Automated Image Processing using the Concept of Colorimetry", Second International Symposium on Computer Vision and the Internet (VisionNet'15), Elsevier, Procedia Computer Science 58, 453 - 460. 
[12] Merugu Suresh, Kamal Jain, 2013, “To Generate High Resolution Images (Conventional Subpixel) from Low Resolution Satellite Images: Colorimetry Concept" ISG \&ISRS, Visakhapatnam, India, 4-6 ${ }^{\text {th }}$ Dec, 2013.

[13] Merugu Suresh, Kamal Jain, 2014, “A Review of Some Information Extraction Methods, Techniques and their Limitations for Hyperspectral Dataset" International Journal of Advanced Research in Computer Engineering \& Technology (IJARCET), Volume 3 Issue 3, March 2014, ISSN: 2278 - 1323, pp 2394-2400.

[14] Merugu Suresh, Kamal Jain,2013 "Sub Pixel Analysis on Hypothetical Image by using Colorimetry" International Journal of Recent Technology and Engineering(IJRTE), ISSN: 2277-3878, Volume 2, Issue-4, September 2013.

[15] Niroumand M. J., Safadarinezhad A.R. ,Shaebi M.R (2012)" A Novel approach to superresolution mapping of multispectral imagery based on Pixel swapping technique". Annals of Photogrammetry And Remote Sensing Volume 1-7.
[16] Raymond Bonnett and Campbell (2002), "Introduction to Remote Sensing", $3^{\text {rd }}$ Edition.

[17] Shi, Wenzhong, and Qunming Wang. "Soft-then-hard sub-pixel mapping with multiple shifted images", International Journal of Remote Sensing, 2015.

[18] Tatem, A.J., Lewis, H.G., Atkinson, P.M. and Nixon, M.S. (2001), "Super-resolution target identification from remotely sensed image using a Hopfield neural network," IEEE Transactions on Geoscience and Remote Sensing. 39(4), 781-796.

[19] VERHOEYE; J.-and DE WULF, R., 2002, Land cover mapping at sub-pixel scales using linear optimization techniques. Remote Sensing of Environment, 79, pp. 96104.

[20] Wang, Qunming, Wenzhong Shi, and Peter M. Atkinson. "Sub-pixel mapping of remote sensing images based on radial basis function interpolation", ISPRS Journal of Photogrammetry and Remote Sensing, 2014. 